TITLE:

\title{
High-throughput analyses of gene functions on a cell chip by electroporation.
}

$\operatorname{AUTHOR}(\mathrm{S}):$

Kato, Koichi; Iwata, Hiroo

\section{CITATION:}

Kato, Koichi ...[et al]. High-throughput analyses of gene functions on a cell chip by electroporation.. Methods in molecular biology 2011, 706: 181-190

\section{ISSUE DATE:}

2011

URL:

http://hdl.handle.net/2433/141856

\section{RIGHT:}

The final publication is available at www.springerlink.com; This is not the published version. Please cite only the published version.; この論文 は出版社版でありません。引用の際には出版社版をご確認ご利用くだ さい。 


\title{
High-Throughput Analyses of Gene Functions on a Cell Chip by Electroporation
}

Koichi Kato and Hiroo Iwata*

Institute for Frontier Medical Sciences, Kyoto University, 53 Kawahara-cho, Shogoin,

Sakyo-ku, Kyoto 606-8507, Japan

*Corresponding author. E-mail: iwata@frontier.kyoto-u.ac.jp

\begin{abstract}
Genome-wide functional annotation of genes is one of the major challenges in current biology. Such investigation requires a high-throughput methodology for the efficient and parallel overexpression or silencing of multiplexed genes in living cells. The transfection method described here employs an electric pulse and a cell chip technology, and provides a possibility of analyzing gene functions in a high-throughput manner.
\end{abstract}

Key Words: Electroporation; microarray; gene transfer; plasmid DNA; small-interfering RNA; poly(ethyleneimine); green fluorescent protein; self-assembled monolayer; functional genomics 


\section{Introduction}

Manipulation of gene expression in living organisms provides significant information on gene functions. To date, a various kind of methods have been developed for investigations of genes by gain-of-function study using plasmid DNA or loss-of-function study using small interfering RNAs (siRNAs). In these studies, transfection microarrays have been developed for the high-throughput transfection of nucleic acids into living mammalian cells.

The Human Genome Project completed in 2003 provided us the complete sequence of the 3 billion DNA subunits in the human genome (1). As a result, the number of human genes was estimated to be 20,000-25,000 (2). Accordingly the next challenge is to interpret the function of human genes in a genome-wide. This would be possible by large-scale functional genomics study in which individual genes are overexpressed or silenced in living cells. For this challenge, we need a novel method that allows to efficiently transfect a large panel of plasmids or siRNAs separately into cells in a high-throughput manner.

Transfection microarrays have been developed by several research groups (3-10). In this technology, a panel of plasmids or siRNAs is arrayed on a small chip and then cells are directly plated onto the array for transfection. In many cases, transfection is promoted by complexing nucleic acids with a cationic lipid enhancer. However, the efficiency of transfection is limited and, more importantly, transfection cannot be temporally controlled. The method (11-17) that uses electric pulses to trigger the transfection of plasmids or 
siRNAs permits more efficient and temporally-controlled transfection on a chip.

This chapter introduces the method for the electroporation of cells with plasmids or siRNAs on a micropatterned electrode chip. Protocols are described for the case of overexpression of enhanced green fluorescent protein (EGFP) and silencing of endogeneous EGFP gene by siRNA. It seems that these examples help establishing an experimental setup for the parallel transfer of multiplexed plasmids or siRNAs. The protocols described here assume the use of specific apparatuses that we have used (thermal evaporator, ultraviolet lamp, fluorescence microscope, imaging software, etc.), but not restricted to them if similar experimental conditions can be achieved.

\section{Materials}

\subsection{Plasmids and siRNAs}

1. pEGFP-C1 and pd2EGFP-N1 (both from Clontech Laboratories, Palo Alto, CA) that code EGFP and destabilized EGFP, respectively, under the control of a cytomegalovirus promoter (see Note 1).

2. Synthetic siRNA specific for EGFP (EGFP-siRNA): sense;

5'-GCAAGCUACCCUGAAGUUCAU-3', antisense;

5'-GAACUUCAGGGUCAGCUUGCC G-3' (Qiagen, Hilden, Germany). Non-specific siRNA (control-siRNA): sense; 5'-UUCUCCGAACGUGUCACGUdTdT-3', antisense; 
5'-ACGUGACACGUUCGGAGAAdT dT-3' (Qiagen). The control-siRNA is used as a negative control.

\subsection{Cell Culture}

1. Human embryonic kidney cells (HEK293) that can be obtained from, for example, Health Science Research Resources Bank, Tokyo, Japan. (see Note 2).

2. HEK293 cells stably transformed with pd2EGFP-N1 (see Note 3).

2. Minimal essential medium (MEM) (Invitrogen Corp., Carlsbad, CA) supplemented with $10 \%$ heat-inactivated fetal bovine serum (FBS), $100 \mathrm{U} / \mathrm{ml}$ penicillin, and 0.1 $\mathrm{mg} / \mathrm{ml}$ streptomycin.

\subsection{Preparation of Plasmid- or siRNA-Loaded Electrodes}

1. Glass plate $(24 \mathrm{~mm} \times 26 \mathrm{~mm} \times 1.5 \mathrm{~mm})$ (Matsunami Glass Ind., Ltd, Osaka, Japan). Standard glass slides cut into the above size can be suitably used.

2. Piranha solution (concentrated sulfuric acid : $30 \%$ hydrogen peroxide solution $=7: 3$ by volume) (see Note 4$)$.

3. Thermal evaporator (V-KS200, Osaka Vacuum Instruments, Osaka, Japan) used for depositing a thin layer of chromium and gold onto glass plates.

4. 1-Hexadecanethiol (Tokyo Kasei Kogyo Co., Tokyo, Japan) dissolved in ethanol to a 
concentration of $1 \mathrm{mM}$. The solution should be made fresh as required.

5. Methoxypoly(ethylene glycol) thiol (SUNBRIGHT ME-050SH, Mw $=5000, \mathrm{NOF}$

Corp., Tokyo, Japan) dissolved in a $1: 6$ mixture of water and ethanol. The solution should be made fresh as required.

5. Quartz-based chromium photomask having an array of tiny windows.

6. Ultra-high-pressure mercury lamp (500 W, Optical Modulex SX-UI500HQ, Ushio, Inc., Osaka, Japan).

7. 11-Mercaptoundecanoic acid (Aldrich Chemical Co., Milwaukee, WI) dissolved in ethanol to a concentration of $1 \mathrm{mM}$. The solution should be made fresh as required.

8. Branched poly(ethyleneimine) (PEI) (Aldrich) with an average molecular weight of 800-2000. PEI is dissolved in phosphate buffered saline (PBS) to a concentration of $1 \%$ (w/v). The solution is adjusted to $\mathrm{pH} 7.4$ with $\mathrm{HCl}$ solution and stored at $4{ }^{\circ} \mathrm{C}$.

\subsection{Determination of Loaded Plasmid and siRNA}

1. Rhodamine-conjugated plasmid DNA (pGeneGrip ${ }^{\mathrm{TM}}$ Rhodamine/GFP, Gene Therapy Systems, Inc., San Diego, CA).

2. EGFP-siRNA conjugated with rhodamine at the 3'-end (EGFP-siRNA-Rho): sense; 5'-GCAAGCUGACCCUGAAGUUCAU-3', antisense; 5'-GAACUUCAGGGUCAGCUUGCCG-3' (Qiagen). 
3. Fluorescence microscope (MZ FLIII fluorescence stereomicroscope, Leica, Germany) equipped with a cooled-CCD camera (ORCA-ER, Hamamatsu Photonics K.K., Shizuoka, Japan).

4. AQUALite digital imaging software (Hamamatsu Photonics).

\subsection{Electroporation}

1. Electroporation setup (Fig. 1) connected to a pulse generator (ElectroSquare-Porator T820, BTX, San Diego, CA or Gene Pulser Xcell, Bio-Rad, Hercules, CA).

2. Standard cell culture facility with $\mathrm{CO}_{2}$ incubator, laminar flow clean bench, autoclave, centrifuge, etc.

4. $70 \%$ Ethanol solution for disinfecting.

5. Sterilized and cooled PBS.

6. Inverted fluorescence microscope (BX-51, Olympus, Tokyo, Japan).

\section{Methods}

\subsection{Preparation of plasmid- or siRNA loaded electrodes}

1. A glass plate is treated with a Piranha solution at room temperature for $5 \mathrm{~min}$ to remove impurities. The cleaned glass plate is thoroughly washed with deionized water and 2-propanol, and dried under a stream of nitrogen gas (see Note 5). 
2. A thin primer layer of chromium (thickness: $1 \mathrm{~nm}$ ) is deposited onto the glass surface, and then a gold layer (thickness: $19 \mathrm{~nm}$ ) is further deposited on top of the chromium layer in a continuous process using a thermal evaporator operated at a pressure of $3-4 \times$ $10^{-4} \mathrm{~Pa}($ see Note 6$)$.

3. Immediately after deposition, the plate is immersed in $1 \mathrm{mM} \mathrm{1-hexadecanethiol} \mathrm{solution}$ at room temperature for $24 \mathrm{~h}$ to form a self-assembled monolayer (SAM) of the alkanethiol on the gold-evaporated glass plate. Alternatively, methoxypoly(ethylene glycol) thiol is used for the preparation of a cell-repelling SAM. The plate is then washed with ethanol and water, and dried under a stream of nitrogen gas.

4. The photomask is overlaid to the surface of the SAM, and then the monolayer surface is irradiated by UV light through the photomask from a ultra-high-pressure mercury lamp at a distance of $20 \mathrm{~cm}$ under atmospheric condition for $2 \mathrm{~h}$. The irradiated plate is then washed with ethanol and water to remove photo-cleaved alkanethiols (see Note 7).

5. Immediately after the above procedure, the plate is immersed in $1 \mathrm{mM}$ 11-mercaptoundecanoic acid solution at room temperature for $3 \mathrm{~h}$ to form a $\mathrm{COOH}$-terminated SAM within the gold spots. Then the glass plate is washed with ethanol to remove unreacted alkanethiols (see Note 8).

6. An aliquot of PEI solution is manually applied to the carboxylic acid-terminated spots $(\sim 0.2 \mu \mathrm{L}$ per spot) and the solution is kept for $30 \mathrm{~min}$ at room temperature to 
electrostatically adsorb PEI to the spots. Then, the plate was washed with water to remove weakly adsorbed PEI, disinfected with $70 \%$ ethanol and air-dried in a sterile laminar flow hood (see Note 9).

7. A sterilized solution of plasmid or siRNA $(50 \mu \mathrm{g} / \mathrm{ml})$ in PBS (pH 7.4) is applied to the cationic polymer-modified spots and allow for the adsorption of plasmid or siRNA for 2 $\mathrm{h}$ at room temperature. The resulting plasmid- or siRNA-loaded glass plate is extensively washed with PBS and used for later experiments without drying (see Note 10).

\subsection{Determination of Loaded Plasmid and siRNA}

1. To determine the amount of plasmid loaded on the electrode surface, pGeneGrip $^{\mathrm{TM}}$ Rhodamine/GFP is loaded by the same procedure as described above but in the dark, and visualized with a fluorescence microscope equipped with a cooled-CCD camera. In the case of siRNA-loaded electrodes, EGFP-siRNA- Rho is used.

2. Fluorescence intensity is determined on a plasmid- or siRNA-loaded spot using the imaging software and converted to their loading amounts using calibration curves that are obtained by depositing the plasmid or siRNA of known amounts on the PEI-adsorbed gold surface (see Note 11). 


\subsection{Electroporation}

1. A sterilized silicone frame (Fig. 1A) is attached to the plasmid- or siRNA-loaded electrode to confine the cell culture region.

2. A suspension of HEK293 cells is transferred within the silicone frame at a density of 45,000 cells $/ \mathrm{cm}^{2}$ for plasmid-loaded electrode or 60,000 cells $/ \mathrm{cm}^{2}$ for siRNA-loaded electrode.

3. The plate is placed in a polystyrene cell culture dish. MEM containing 10\% FBS, 100 $\mathrm{U} / \mathrm{ml}$ penicillin, and $0.1 \mathrm{mg} / \mathrm{ml}$ streptomycin is added to cover an entire surface of the plate. Then, cells are cultured at $37{ }^{\circ} \mathrm{C}$ under $5 \% \mathrm{CO}_{2}$ atmosphere normally for $24 \mathrm{~h}$ to allow for the attachment of cells to the electrode surface (see Note 12).

3. The plate with cells are carefully washed with PBS, and the inner space of the silicone frame is filled with cold PBS.

4. A counter electrode (gold-evaporated glass plate; Fig. 1) is placed on the frame with the gold surface down at a distance of 0.5-2 $\mathrm{mm}$ (see Note 13) above the plasmid-loaded electrode. Lower (cathode) and upper (anode) electrodes are connected to a pulse generator.

5. Cells are treated with a single electric pulse at field strength of $75-260 \mathrm{~V} / \mathrm{cm}$ for duration of $10 \mathrm{~ms}$ (see Note 14).

6. After 10-min incubation at room temperature, PBS is replaced with MEM containing 
$10 \%$ FBS, $100 \mathrm{U} / \mathrm{ml}$ penicillin, and $0.1 \mathrm{mg} / \mathrm{ml}$ streptomycin. Then the cells are further cultured at $37{ }^{\circ} \mathrm{C}$ under $5 \% \mathrm{CO}_{2}$ atmosphere.

7. Cells are observed $48 \mathrm{~h}$ after electroporation using a fluorescence microscope to assess the expression/silencing of EGFP. As an example, photographs of cell chips that display EGFP-expressing cells are shown in Fig. 2 for plasmids and Fig. 3 for siRNAs.

8. For a quantitative study, fluorescent intensity of EGFP is determined for every spot using a digital imaging software such as AQUA-Lite (Hamamatsu Photonics).

\section{Note}

1. The plasmids are expanded in Escherichia coli and purified using, for example,

EndoFree Plasmid Maxi Kit (Qiagen, Hilden, Germany) according to the manufacturer's instruction. The plasmids are dissolved in $10 \mathrm{mM}$ Tris- $\mathrm{HCl}$ buffer $(\mathrm{pH}$ 8.0) containing $0.1 \mathrm{mM}$ ethylenediamine- $N, N, N^{\prime}, N^{\prime}$ - tetraacetic acid (EDTA) and stored at $-20{ }^{\circ} \mathrm{C}$ until use.

2. HEK293 cells are routinely maintained in MEM supplemented with 10\% FBS, 100 $\mathrm{U} / \mathrm{ml}$ penicillin, and $0.1 \mathrm{mg} / \mathrm{ml}$ streptomycin at $37{ }^{\circ} \mathrm{C}$ under a $5 \% \mathrm{CO}_{2}$ atmosphere.

3. HEK293 cells stably transformed with pd2EGFP-N1 (d2EGFP-HEK) are obtained by standard lipofection and subsequent selection in the presence of geneticin.

4. It is a hazardous solution and must be handled with care. 
5. This chapter assumes the use of gold electrode as a platform for the preparation of transfection microarrays. A transparent electrode made of indium-tin-oxide (ITO) can be used as an alternative substrate (12). In this case, the layer-by-layer assembly of PEI and plasmid DNA is efficient for the stable loading and efficient transfection.

6. The thickness of chromium and gold layers can be monitored using a quartz crystal microbalance sensor (Inficon, Leybold AG, Köln, Germany) equipped in a sample chamber.

7. A holder for a glass plate and a photomask helps preventing dislocation of the photomask during UV irradiation. This process produces an array of spots presenting a pristine gold surface. We routinely prepare an array of circular spots with a diameter of $1 \mathrm{~mm}$, to which more than 2000 cells can adhere. The spot size can be easily reduced down to, for instance, $0.2 \mathrm{~mm}$ by changing the design of a photomask, but it must be taken into consideration that too less number of cells affects the reliability of data obtained from a single spot.

8. This process produces an array of spots presenting carboxylic acid-terminated SAM which is surrounded by the methyl-terminated SAM.

9. PEI can be replaced with highly-cationic amidoamine dendrimers for the enhancement of electroporation efficiency (15). Modification of PEI-adsorbed surface with carboxylated carbon nanotubes also enhances electroporation efficiency (13). 
10. Transfection efficiency is greatly impaired by storage of the plasmid-loaded electrode, due to water evaporation from arrayed plasmids. The addition of monosaccharide (glucose, fructose), disaccharide (trehalose, sucrose), or trisaccharide (raffinose) to a concentration of $10 \%(\mathrm{w} / \mathrm{v})$ serves to retain transfection efficiency at a reasonably high level after storage for up to 30 days at $-20{ }^{\circ} \mathrm{C}(17)$.

11. In a typical case, loading amounts reach $0.1-0.5 \mu \mathrm{g} / \mathrm{cm}^{2}$ for plasmid DNA and $0.01-0.03 \mu \mathrm{g} / \mathrm{cm}^{2}$ for siRNA.

12. In the moment of electroporation, confluency at $70-80 \%$ is recommended. Plasmids are released only when an electric pulse is applied. Depending on the specific purposes, a culture period before electric pulsing can be prolonged up to $72 \mathrm{~h}$ without considerable reduction in transfection efficiency.

13. A glass plate having a gold layer (200 $\mathrm{nm}$ in thickness) without SAM is used as a counter electrode. Use sterilized tweezers to handle electrodes. A distance between upper and lower electrodes should be optimized for the specific experimental setup.

14. An electric field strength has great influence on transfection efficiency and should be optimized for specific cases.

\section{Acknowledgements}

The part of this work was supported by Grants-in-Aid for Scientific Research (No. 
15310090), Ministry of Education, Culture, Sports, Science and Technology (MEXT) and Kobe Cluster, the Knowledge-Based Cluster Creation Project, MEXT.

\section{References}

1. International Human Genome Sequencing Consortium (2001) Initial sequencing and analysis of the human genome. Nature 409, 860-921.

2. Tyers, M., Mann, M. (2003) From genomics to proteomics. Nature 422, 193-197.

3. Ziauddin, J., Sabatini, D. M. (2001) Microarrays of cells expressing defined cDNAs. Nature 411, 107-110.

4. Kumar, R., Conklin, D. S., Mittal, V. (2003) High-throughput selection of effective RNAi probes for gene silencing. Genome Res. 13, 2333-2340.

5. Mousses, S., Caplen, N., Cornelison, R., Weaver, D., Basik, M., Hautaniemi, S., Elkahloun, A. G., Lotufo, R. A., Choudary, E. R., Suh, E., Kallioniemi, O. (2003) RNAi microarray analysis in cultured mammalian cells. Genome Res. 13, 2341-2347.

6. Yamauchi, F., Kato, K., Iwata, H. (2004) Micropatterned, self-assembled monolayers for fabrication of transfected cell microarrays. Biochim. Biophys. Acta 1672, 138-147.

7. Yoshikawa, T., Uchimura, E., Kishi, M., Funeriu, D. P., Miyake, M., Miyake, J. (2004) Transfection microarray of human mesenchymal stem cells and on-chip siRNA gene knockdown. J. Controlled Release 96, 227-232. 
8. Fujimoto, H., Yoshizako, S., Kato, K., Iwata, H. (2006) Fabrication of cell-based microarrays using micropatterned alkanethiol monolayers for the parallel silencing of specific genes by small-interfering RNA. Bioconjugate Chem. 17, 1404-1410.

9. Fujimoto, H., Kato, K., Iwata, H. (2008) Use of microarrays in transfection of mammalian cells with dicer-digested small interfering RNAs. Anal. Biochem. 374, $417-422$.

10. Yamauchi, F., Okada, M., Kato, K., Martin, J. L., Iwata, H. (2007) Array-based functional screening for genes that regulate vascular endothelial differentiation of Flk1-positive progenitors derived from embryonic stem cells. Biochim. Biophys. Acta 1770, 1085-1097.

11. Yamauchi, F., Kato, K., Iwata, H. (2004) Spatially and temporally controlled electroporation of adherent cells on plasmid DNA-loaded electrode. Nucleic Acids Res. 32, e187.

12. Yamauchi, F., Kato, K., Iwata, H. (2005) Layer-by-layer assembly of poly(ethyleneimine) and plasmid DNA onto transparent indium-tin oxide electrodes for temporally- and spatially-specific gene transfer. Langmuir 21, 8360-8367.

13. Inoue, Y., Fujimoto, H., Ogino, T., Iwata, H. (2008) Site-specific gene transfer with high efficiency onto a carbon nanotube-loaded electrode. J. R. Soc. Interface 5, 909-918. 
14. Njatawidjaja, E., Iwata, H. (2008) Gene delivery to cells on a miniaturized multiwell plate for high-throughput gene function analysis. Anal. Bioanal. Chem. 392, 405-408.

15. Koda, S., Inoue, Y., Iwata, H. (2008) Gene transfection into adherent cells using electroporation on a dendrimer-modified gold electrode. Langmuir 24, 13525-13531.

16. Fujimoto, H., Kato, K., Iwata, H. (2008) Electroporation microarray for parallel transfer of small interfering RNA into mammalian cells. Anal. Bioanal. Chem. 392, 1309-1316.

17. Fujimoto, H., Kato, K., Iwata, H. (2009) Prolonged durability of electroporation microarrays as a result of addition of saccharides to nucleic acids. Anal. Bioanal. Chem. 393, 607-614. 


\section{Figure Captions}

Fig. 1 (A) Schematic drawings of the electroporation setup. Drawings are not to scale.

Photographs of (B) a basement electrode with a silicone frame and (C) basement and upper electrode connected to a pulse generator. Reproduced from Fujimoto, H., et al. 2008 (16) with permission from Springer (C2008.

Fig. 2 Electroporation of pEGFP-C1 plasmid into HEK293 cells. Cells were seeded on the plasmid-arrayed electrode, cultured for $24 \mathrm{~h}$, and then treated with a single electric pulse at the field strength of $75 \mathrm{~V} / \mathrm{cm}$ for $10 \mathrm{msec}$ duration. Fluorescence images were acquired $48 \mathrm{~h}$ after electric pulsing. (A) Fluorescence image showing EGFP expression in the restricted regions of HEK293 cells $48 \mathrm{~h}$ after electric pulsing. Note that cells are adhered to the entire surface of the electrode, while fluorescently active cells are observed only in the plasmid loaded square islands. (B) Fluorescence image of HEK293 cells transfected on the electrode with a plasmid-loaded island array prepared using the poly(ethylene glycol)-tethering alkanethiol. (C) Higher magnification image of (B). (D) Phase-contrast image of (C). Note that cells adhere only on the islands but not on the surrounding regions. Scale bar: (A and B) $1 \mathrm{~mm}$; (C and D) $200 \mu \mathrm{m}$. Reproduced from Yamauchi, F., et al. 2004 (11) with permission from Oxford University Press (C2004. 
Fig. 3 Electroporation of siRNAs into dsEGFP-HEK cells. (A) Low magnification fluorescence image of d2EGFP-HEK cells electroporated on the microarray that displayed 42 spots arrayed in a $6 \times 7$ matrix. The image was recorded $48 \mathrm{~h}$ after electric pulsing at 240 V/cm for $10 \mathrm{~ms}$. GFPsiRNA was loaded to spots (dark spots) on odd lines from the top; control-siRNA (highlighted with dashed circles) was loaded on even lines. (B) Higher magnification image of cells in (a). Phase-contrast and fluorescence microphotographs are shown for d2EGFP-HEK cells electroporated on the spots with (left) GFP-siRNA and (right) control-siRNA. Scale bar: (A) $1 \mathrm{~mm}$ and (B) $500 \mu \mathrm{m}$. (C) Fluorescence intensity of d2EGFP-HEK cells electroporated on the spots with GFP-siRNA and control-siRNA. The fluorescence intensities were determined $48 \mathrm{~h}$ after electroporation. The data are expressed as mean \pm standard deviation for 12 spots on two independent microarrays. An asterisk indicates statistical significance $(\mathrm{p}<0.05)$ by Student's $t$-test. Reproduced from Fujimoto, H., et al. 2008 (16) with permission from Springer (C2008. 